\title{
Sociomuseologia e Arqueologia Pós-processual: conexões no contexto brasileiro contemporâneo.
} Camila Moraes Wichers ${ }^{1}$

\section{Resumo}

Nesse artigo sintetizo aspectos fundamentais da musealização do patrimônio arqueológico. Inicio o texto com uma breve caracterização do campo da Arqueologia no Brasil. Passo, em seguida, ao delineamento de algumas premissas que nortearam a construção da pesquisa, ressaltando a necessária interface entre a Arqueologia e a Museologia. Apresento, então, o entrelaçamento entre a Sociomuseologia e as vertentes da arqueologia pósprocessual como caminho de superação dos obstáculos evidenciados no contexto contemporâneo. Por fim, sintetizo o estudo de caso da tese, onde apliquei as perspectivas da Sociomuseologia na concepção de um programa de socialização dos recursos arqueológicos resgatados no âmbito da Ferrovia Transnordestina. O programa delineado foi entendido enquanto síntese da complexa, mas necessária, teia de relações entre Museologia e Arqueologia no cenário brasileiro contemporâneo.

Palavras Chave: Património arqueológico; Arqueologia e museologia; Arqueologia Pós-processual;

\footnotetext{
${ }^{1}$ Doutorada em Arqueologia pela Universidade de São Paulo, Brasil(2012), Professor Adjunto da Universidade Federal de Goiás, Brasil camora21@yahoo.com.br
} 


\begin{abstract}
In this article I summarize fundamental aspects of the musealization processes of archaeological heritage. I shall start this text with a short description of the field of archeology in Brazil; presenting then, the design of some assumptions which have guided the construction of this research, emphasizing the necessary interface between Archeology and Museology. I will also introduce the interweaving between Sociomuseology and the strands of post-procedural archeology as a way of overcoming the obstacles evidenced in the contemporary context. In conclusion, I shall synthesize the thesis' case study, where I have applied the prospects of Sociomuseology in designing a program of socialization of the archeological resources rescued under the Transnordestina Railroad. The outline of the program was understood while synthesis of the complex, however necessary, web of relations between Museology and Archeology in a contemporary Brazilian scenario was made.
\end{abstract}

Keywords: Archaeological heritage; Archeology and museology; postprocedural archeology.

\title{
Introdução
}

Os vestígios arqueológicos musealizados são frutos de seleções condicionadas por contextos sociais, paradigmas teóricos e opções metodológicas, imbricados em relações de poder (FOUCAULT, 1979). Dessa feita, as pesquisas arqueológicas são práticas de colecionamento ${ }^{2}$.

Em uma perspectiva histórica, os vestígios arqueológicos estão associados ao colecionismo, aos gabinetes de curiosidades e à própria gênese dos museus. Assim como os museus, a Arqueologia também esteve associada à colonização,

\footnotetext{
2 Regina Abreu (2007) aplicou o conceito de "práticas de colecionamento" ao contexto das pesquisas antropológicas, aqui aplico esse conceito ao campo de estudo da Arqueologia.
} 
ao saque e ao extermínio. No Brasil, o 'nascimento' da Arqueologia ocorreu no cenário das instituições museológicas. Contudo, essa relação de cumplicidade - para o bem e para o mal - foi dando lugar a um estranhamento. Embora fisicamente associados, uma vez que a pesquisa arqueológica gera um semnúmero de objetos patrimoniais que se destinam às reservas técnicas dos museus, a relação entre instituições museológicas e patrimônio arqueológico no Brasil tem sido pautada por caminhos de aproximação, rotas de afastamento e pontos de colisão que caracterizaram a relação dos campos científicos (BOURDIEU, 1997) da Museologia e da Arqueologia no Brasil.

As diferentes configurações entre patrimônio arqueológico, identidade e memória foram e são determinantes para a compreensão dessa relação, uma vez que os museus são, por excelência, espaços de construção identitária. Na medida em que o patrimônio arqueológico desvelado pelas pesquisas se aproxima ou se afasta de determinadas construções identitárias e mnemônicas, a relação com os museus também é de aproximação ou afastamento. Não significa que a aproximação entre patrimônio arqueológico e museus seja a priori positiva. Por vezes, essa cumplicidade serviu ao reforço de identidades globalizantes e totalitárias. Faz-se necessário compreender os processos sociais relacionados ao uso - ou não - do patrimônio arqueológico na construção das identidades, em escala nacional, regional e local. Bruno (1995), ao analisar o panorama brasileiro, indicou a circunscrição das fontes arqueológicas ao terreno das "memórias exiladas", mostrando que o patrimônio arqueológico tem ocupado papel coadjuvante nas interpretações relativas à cultura brasileira. 
Ao longo das últimas décadas, no Brasil, a consolidação da legislação ambiental impulsionou o crescimento de projetos de pesquisa arqueológica no âmbito de empreendimentos de natureza diversa, configurando o campo de atuação da denominada Arqueologia Preventiva ${ }^{3}$. Esses projetos correspondem à grande parte dos estudos arqueológicos realizados no país, gerando acervos significativos, quer do ponto de vista quantitativo, quer qualitativo, os quais podem e devem ser alvo de processos museológicos. No entanto, uma parcela inexpressiva desses estudos é inserida em processos de musealização que envolvam toda a cadeia operatória museológica.

Nesse texto optei por apresentar alguns pontos que julgo fundamentais para a compreensão dessa problemática, destacando o entrelaçamento entre a Sociomuseologia e as vertentes da Arqueologia Pós-processual como caminho de superação dos obstáculos apresentados ao longo do trabalho.

\section{Arqueologia: conformação do campo contemporâneo}

A compreensão da configuração do campo científico da Arqueologia no cenário brasileiro contemporâneo envolve necessariamente o entendimento da inserção da pesquisa arqueológica no âmbito da Arqueologia Preventiva, que representa cerca de $98 \%$ das pesquisas em andamento no país. $\mathrm{A}$ correlação entre práxis arqueológica e um modelo de

O termo Arqueologia Preventiva foi antecedido por designações como Arqueologia de Salvamento e Arqueologia de Contrato. Essas denominações se referem ao mesmo fenômeno: pesquisas arqueológicas realizadas no âmbito de obras potencialmente lesivas ao meio ambiente. 
crescimento econômico, que não significa desenvolvimento humano, deve ser considerada na análise da relação entre Arqueologia e Museologia, pois traz à tona desafios específicos. Convém primeiramente rastrearmos alguns pontos importantes da configuração da Arqueologia Preventiva no Brasil.

Em 1961, foi sancionada no Brasil a lei no 3.924 de proteção ao patrimônio arqueológico ${ }^{4}$. Segundo essa lei, "os sítios arqueológicos [e seu conteúdo cultural] são considerados bens patrimoniais da União." [Art. $7^{\circ}$ ]. Na referida lei são considerados monumentos arqueológicos ou pré-históricos, as jazidas, sítios e inscrições rupestres de "paleoameríndios" do Brasil, não sendo abordados os contextos arqueológicos advindos de períodos cronológicos posteriores à colonização europeia. Embora contássemos com a referida lei, durante décadas os empreendimentos instalados no país não envolviam qualquer estudo arqueológico.

No começo da década de 1980 foi promulgada a legislação que inaugurou a Política Nacional de Meio Ambiente, estabelecendo uma política de conservação ambiental que incluía também os recursos culturais. Como consequência, a Arqueologia, passou a ser solicitada a dar a sua contribuição ao processo de planejamento ambiental, seja na esfera regional, seja na esfera urbana (CALDARELLI, 1996). Monticelli (2005) chama atenção para o hiato de vinte anos entre a legislação que passou a considerar os sítios arqueológicos como bens da União, datada de 1961, a adoção de uma política ambiental que

\footnotetext{
$4 \quad$ Vale lembrar que, anteriormente, em 1937, o patrimônio arqueológico foi contemplado no Decreto-Lei 27/1937 desde que tivesse "excepcional valor arqueológico".
} 
garantisse a obrigatoriedade de intervenções arqueológicas nas obras.

A Constituição Federal de 1988 veio fortalecer os instrumentos legais de preservação, ao considerar os sítios arqueológicos como patrimônio cultural brasileiro, garantindo sua guarda e proteção. A Constituição representou um passo importante, pois, ao incluir os sítios arqueológicos na categoria de bens da União, ratificando a lei de 1961, estendeu a proteção a todos esses bens, tombados ou não (SALADINO, 2010).

Com vistas a fazer cumprir as disposições da Constituição, foi criada uma portaria normativa interna para orientar o recebimento dos pedidos de autorização de pesquisas arqueológicas. Dessa forma, por intermédio da portaria nㅇ 7/ 1988 ficou consolidado o papel regulador do Instituto do Patrimônio Histórico e Artístico Nacional - IPHAN frente à comunidade científica arqueológica.

Em 2002, a Portaria IPHAN 230/02 normatizou a pesquisa arqueológica no âmbito de estudos de impacto e de licenciamento ambiental. Essa portaria foi especialmente dedicada à regularização dos procedimentos de arqueologia preventiva no licenciamento ambiental, estabelecendo o compasso necessário entre as licenças ambientais e a preservação do patrimônio arqueológico. Entretanto, a referida portaria estabeleceu rotas de distanciamento entre Arqueologia e Museologia, as quais foram ainda mais aprofundadas a partir da recente publicação da Instrução Normativa N. 01 de 25 de Março de 2015, que revogou a portaria anterior e consagrou o hiato entre práticas arqueológicas e museológicas no âmbito jurídico, uma vez que não menciona o papel dos museus e dos profissionais de Museologia no campo da preservação do 
patrimônio arqueológico, fazendo menção apenas aos profissionais da conservação no campo da salvaguarda e aos pedagogos no campo da educação patrimonial. Cabe apontar que no Brasil o IPHAN é responsável pelo patrimônio arqueológico, enquanto o IBRAM - Instituto Brasileiro de Museus, está direcionado aos museus e processos museológicos.

Entre 2003 e 2014 foram realizadas 10164 pesquisas arqueológicas no país, segundo dados obtidos nas portarias de pesquisa publicadas no Diário Oficial da União. Esse crescimento tem possibilitado o incremento do campo, mas também tem trazido desafios, em especial, àqueles correlacionados ao papel político e social da Arqueologia em contextos de expropriação material e simbólica das comunidades (MORAES WICHERS 2010). No que concerne às coleções geradas, é recorrente a emissão de endossos por uma instituição inserida em determinada unidade federativa para pesquisas realizadas em outro Estado, o que em teoria, significa o deslocamento de acervos entre territórios. Quando analisamos o número de endossos fornecidos por cada instituição, detectamos que $51 \%$ das pesquisas realizadas no Brasil no período analisado foram apoiados por apenas 20 instituições, revelando uma concentração significativa das coleções geradas. No que tange as tipologias e tutelas administrativas das instituições mapeadas, evidenciamos o predomínio de laboratórios e centros de pesquisa, em detrimento de instituições museológicas. Temos também o predomínio de instituições privadas, em detrimento de instituições públicas.

O aumento exponencial das pesquisas, assim como das instituições que emitem apoios/ endossos, denota uma complexidade crescente do campo da Musealização da 
Arqueologia. O abandono do modelo museológico nas tipologias das instituições e a crescente inserção de instituições privadas, sem uma legislação especifica que garanta a preservação desses acervos, inspira cuidados.

No cenário contemporâneo, o aumento dos debates acerca da necessária democratização da seleção, produção e acesso ao patrimônio cultural, e aí se insere o patrimônio arqueológico, tem um papel decisivo na compreensão do afastamento entre Arqueologia e Museologia. Isso porque a expansão das pesquisas e das instituições envolvidas com o tema não têm significado uma ampliação proporcional do acesso da sociedade a esse patrimônio. Avanços ocorreram, mas os desafios também aumentaram.

Por seu turno, a proliferação das novas práticas no seio da Museologia evidencia a efervescência do mundo museológico. Cada vez mais, ganham espaço processos museológicos deflagrados a partir do olhar das comunidades. Assim, a prática arqueológica reservada legalmente aos arqueólogos enfrenta um impasse. No Brasil, estes objetos são patrimônio da União, o que reserva sua manipulação aos especialistas. Dessa forma, coleções e narrativas arqueológicas representam um desafio específico ao fazer museológico contemporâneo, particularmente à Sociomuseologia, pois não permitem a necessária intervenção das comunidades na seleção do patrimônio. A violência epistêmica marca de forma perversa a antropofagia arqueológica no contexto brasileiro, ainda mais em um cenário onde, muitas vezes, o patrimônio arqueológico é atrelado a empreendimentos que acarretam impactos negativos nas sociedades envolvidas. Trata-se de um ponto de colisão entre prática museológica e arqueológica no cenário brasileiro contemporâneo. 


\section{Algumas premissas}

Defendo que a prática Arqueológica e suas correspondentes coleções e narrativas podem participar de processos de construção identitária e da configuração das noções de pertencimento, em uma perspectiva crítica. Mais que um vestígio do passado, o patrimônio arqueológico é um recurso, um fenômeno contemporâneo, construído no presente. Contudo, esse processo requer um olhar interdisciplinar.

A necessidade de superação das barreiras existentes entre a Arqueologia e a sociedade me levou à escolha do olhar museológico, uma vez que a Museologia, ao preservar os indicadores da memória, transformando-os em herança patrimonial, contribui para o fortalecimento das noções de identidade e pertencimento (BRUNO, 2000). Os milhares de vestígios advindos das pesquisas arqueológicas, agora definitivamente espalhadas por todo o Brasil, ganham sentido quando explorados a partir de uma perspectiva museológica contemporânea, que visa à construção de uma nova prática social a partir de ações de preservação do patrimônio cultural.

Ademais, a Arqueologia, ao lidar com as relações sociais associadas à produção, uso e descarte da cultura material, e a Museologia, ao compreender, teorizar, sistematizar e aprimorar a relação entre sociedade e patrimônio cultural, lançam olhares por vezes entrecruzados para os mesmos fenômenos. Arqueologia e Museologia têm, assim, caminhos entrelaçados.

A escolha do olhar museológico deve-se ao fato de que a interface entre Arqueologia e Museologia permite que essas áreas de conhecimento desempenhem suas funções em todo seu 
potencial. A Musealização da Arqueologia tem o potencial de construir caminhos para a preservação almejada, compreendendo que o sentido da preservação está na dinamização [ou uso social] do bem cultural preservado (CHAGAS, 1998).

\section{Sociomuseologia e Arqueologias Pós-Processuais: um diálogo profícuo}

Advogo que a interface entre Museologia e Arqueologia é fundamental para o aprimoramento do uso do patrimônio arqueológico como recurso cultural. Contudo, falo aqui da interação de vertentes específicas desses campos, implicadas com o uso político e social dos museus e do patrimônio arqueológico. O desenvolvimento de processos museológicos alinhados às perspectivas da Sociomuseologia requer também outro fazer da Arqueologia, largamente discutido nos paradigmas pós-processuais.

Desde a segunda metade do século passado, expectativas e desafios presentes em diversos documentos produzidos por segmentos dos campos Museológico e Arqueológico vêm convergindo para uma mesma preocupação: qual o papel social do patrimônio no mundo contemporâneo?

Nas últimas décadas, a Museologia tem passado por mudanças teórico-metodológicas significativas, num esforço constante de democratização não apenas do acesso, mas também da seleção e produção do patrimônio cultural. Nesse sentido, a Sociomuseologia procura sintetizar o esforço de adequação das instituições museológicas à sociedade contemporânea (MOUTINHO, 1993; PRIMO, 1999, 2007). 
Por sua vez, as arqueologias pós-processuais têm salientado a subjetividade do conhecimento arqueológico, construído no presente, a partir de contextos sociais, políticos, econômicos e culturais que influenciam a produção científica (SHANKS, 1994).

Convém esmiuçarmos algumas características dessas arqueologias pós-processuais. O 'pós' que caracteriza essas arqueologias está associado tanto ao fato dessas posturas se colocarem como críticas ao paradigma processual, que as antecedeu, como a sua aproximação às filosofias pós-modernas e à crítica pós-colonial.

Longe de ser homogênea, a Arqueologia pós-processual "É um saco de gatos. Esta arqueologia tem sido provocativa, inquietante, instigadora e ousada em suas propostas" (REIS, 2004). Optei por utilizar as "arqueologias pós-processuais", devido à pluralidade de abordagens dessa corrente.

Uma das principais questões colocadas pelas arqueologias pós-processuais reside nos significados simbólicos dos vestígios arqueológicos, que variam de contexto para contexto. Os arqueólogos pós-processualistas colocam o indivíduo como ator social, cujo contexto dará o significado ao registro arqueológico. Essas abordagens aceitam, assim, a falta de consenso nas interpretações do passado. É justamente nessa abertura, conclamada por Pearson e Shanks (2001 Apud REIS, 2004), que reside o entrelaçamento com a Sociomuseologia, pois tal abertura possibilita novas leituras e ressignificações do contexto arqueológico a partir das comunidades. A 'palavra' do arqueólogo é uma, dentre outras opiniões sobre o passado, pois há muitas e plausíveis interpretações sobre o registro 
arqueológico. Os arqueólogos são, portanto, entendidos como construtores e intérpretes do passado (SHANKS \& TILLEY, 1987).

Outro ponto importante é que as arqueologias pósprocessuais devotam especial atenção aos cuidados e responsabilidades referentes ao conteúdo das mensagens construídas sobre o passado, no âmbito da denominada Arqueologia Pública ${ }^{5}$.

Dessa forma, os fenômenos sociais e culturais contemporâneos revelam o surgimento de arqueologias pósprocessuais que procuram debater aspectos que contribuem para criticar as desigualdades da sociedade onde vivemos (ZARANKIN, 2002). No Brasil, essas ideias vêm sendo, pouco a pouco, inseridas na agenda das pesquisas arqueológicas.

Alguns estudos têm buscado salientar a diversidade cultural das populações indígenas com a participação ativa das mesmas, outros estão ressaltando as diversas interpretações de um mesmo contexto arqueológico no âmbito de arqueologias híbridas. Destaca-se o potencial da Arqueologia Histórica em construir a história de segmentos da sociedade que em raras ocasiões têm condições de deixar registros escritos sobre si próprios. Algumas pesquisas arqueológicas vêm buscando construir narrativas polifônicas acerca do passado, em seus múltiplos contextos, desde o estudo de populações quilombolas, passando por vestígios associados a revoltas populares, a valorização dos conhecimentos tradicionais na construção de

$5 \quad 0$ surgimento da primeira publicação sobre o tema, Public Archaeology em 2000, assinala o amadurecimento das discussões sobre o caráter público da disciplina e sua importância social. Desde a criação do Congresso Mundial de Arqueologia [World Archaeological Congress - WAC], em 1986, a disciplina tem tratado de forma mais sistemática o relacionamento entre a pesquisa e os grupos sociais interessados. 
identidades historicamente marginalizadas, a arqueologia dos desaparecidos durante o regime militar, a questão da repatriação dos objetos arqueológicos, entre outros (MORAES WICHERS, 2010). Essas perspectivas configuram um campo de atuação profícuo para a construção de processos museológicos alinhados à Sociomuseologia.

Dessa maneira, defendo que a interface entre Sociomuseologiae as Arqueologias Pós-Processuais surge como caminho para a superação dos dilemas aqui apresentados. Ainda que, no Brasil, grande parte da pesquisa arqueológica esteja associada à prática de 'especialistas' no âmbito do licenciamento ambiental de empreendimentos diversos, a premissa de que o conhecimento construído é subjetivo abre possibilidades de releitura das coleções e narrativas arqueológicas pelas comunidades. A Sociomuseologia apresenta estratégias que aprimoram a referida leitura. Não obstante, esse campo de interface é marcado por relações dialéticas, pois tanto a Museologia como a Arqueologia se influenciam a todo o momento, ambas produzem narrativas, rompendo com uma possível dicotomia entre produção e socialização do conhecimento.

A construção de uma proposta: o Programa de Socialização dos Recursos Arqueológicos da Ferrovia Transnordestina

Neste item apresento uma proposta para a Musealização da Arqueologia no contexto de um dos empreendimentos que compõe o Programa de Aceleração do 
Crescimento [PAC] do Governo Federal brasileiro: a Ferrovia Transnordestina ${ }^{6}$.

Envolvendo a instalação de 1.728 quilômetros de malha ferroviária, a ferrovia irá ligar os portos de Pecém [Ceará] e Suape [Pernambuco] ao cerrado do estado do Piauí, precisamente no município de Eliseu Martins. Como um empreendimento de grande porte, a ferrovia irá trazer mudanças de ampla extensão, tendo um impacto, no mínimo, reordenador das realidades sociais dos territórios envolvidos. Mais que isso, a Ferrovia Transnordestina será um novo elemento na paisagem do nordeste, representação material de uma nova lógica de circulação e organização espacial que chega a esta porção do território brasileiro. É importante apontar que o território em foco também sofrerá profundas transformações devido à existência de uma dezena de outros empreendimentos em instalação na região nordeste, onde se destaca a controvertida transposição da bacia do Rio São Francisco.

Os estudos arqueológicos têm a peculiaridade de resultar, via de regra, na coleta de vestígios materiais que são projetados na esfera patrimonial, ou seja, esses estudos trazem sempre em seu bojo um problema museológico. No Programa de Gestão dos Recursos Arqueológicos da Ferrovia Transnordestina foram identificados, até o momento, mais de 548 sítios arqueológicos e coletadas 110 mil peças, nos estados do Pernambuco, Ceará e Piauí.

Esse patrimônio pode ser classificado em três grandes conjuntos: 1. Marcas da pedra: sítios com artefatos de pedra

\footnotetext{
$6 \quad$ A equipe da Zanettini Arqueologia iniciou as pesquisas arqueológicas no âmbito da ferrovia em 2007, envolvendo diagnósticos, prospecções e resgates arqueológicos, bem como o monitoramento das obras.
} 
produzidos e utilizados por diferentes sociedades, em diversas temporalidades desde pelo menos 10 mil anos atrás; 2 . Histórias Indígenas: sítios arqueológicos associados aos grupos Tupi e Jê que ocuparam o semiárido nordestino desde entre 1500 anos atrás; 3. Os sertões das sertanejas e sertanejos: aspectos da ocupação desses territórios desde o século XIX até o presente, destacando-se aspectos do trabalho, da moradia, da religiosidade e do universo alimentar.

A musealização das coleções e narrativas arqueológicas traz, nesse contexto, desafios significativos, dada a amplitude do programa. Nesse sentido, a inserção dessa proposta no enquadramento teórico da Sociomuseologia me impulsionou, necessariamente, a um amplo diagnóstico da realidade onde a ferrovia se projeta, considerando que o "Socio" deveria preceder à "Museologia". Ou seja, era imperativo, inicialmente, conhecer as características socioeconômicas e culturais em tela, para, a partir daí, conceber o programa. Ademais, a perspectiva sociomuseológica me levou a problematizar o conceito de desenvolvimento e a trabalhar a partir de um olhar interdisciplinar.

Buscando ultrapassar uma visão homogênea do território foco do estudo, optei por levantar referências locais para a construção do programa de musealização. Nesse sentido, falar da região Nordeste é inventariar os muitos estereótipos e mitos que emergiram com o próprio espaço físico reconhecido no mapa, composto por alguns estados e cidades (ALBUQUERQUE JUNIOR, 2006). É mobilizar todo o universo de imagens negativas e positivas, socialmente reconhecidas e consagradas, que criaram a própria ideia de Nordeste. Tomei 
como premissa que a concepção de um programa 'padronizado' estaria desrespeitando as multifacetadas realidades locais.

Dessa forma, se em um primeiro nível busquei apresentar um perfil mais generalizado dos estados de Pernambuco, Ceará e Piauí, em um segundo nível de análise passei à seleção e ao diagnóstico dos mais de sessentas municípios envolvidos. Foram selecionados polos de atuação dentre esses municípios, a partir do contexto socioeconômico, cultural, panorama museológico e realidade arqueológica, tendo sido priorizados municípios com um número maior de sítios arqueológicos e que também exerçam uma 'influência' nos municípios vizinhos. Os polos selecionados foram: Rio Grande do Piauí, Simplício Mendes e Paulistana, no Piauí; Ouricuri, Salgueiro, Serra Talhada, Custódia, Arcoverde, Altino e Ipojuca, no Pernambuco; Brejo Santo, Abaiara, Iguatu, Quixeramobim, Quixadá, Caucaia, no Ceará. Na proposta, esses polos atuariam como centro das ações do programa de comunicação museológica, em um escala microrregional, deflagrando as ações para os municípios do entorno.

Dentre os dezesseis polos selecionados, apenas sete possuem instituições museológicas, dessa forma colocava-se como desafio pensar estratégias de musealização em um território com instituições ausentes ou enfraquecidas. Outrossim, parti da ideia de que é necessário um equilíbrio entre a salvaguarda e a comunicação, no âmbito da cadeia operatória museológica.

No que concerne ao programa de salvaguarda, defendi dois encaminhamentos: um destinado à formação de coleções de referência a serem destinadas aos municípios polo do programa e outro destinado a estabelecer as instituições de guarda 
definitiva do acervo de pesquisa. Cabe destacar que a 'missão' dessas coleções é diferenciada.

O "Acervo de Pesquisa", mais numeroso, com menor 'apelo' museológico, seria inserido em uma ou mais instituições onde possa desempenhar seu papel enquanto base de estudos que visem à construção de conhecimento na Arqueologia do Nordeste. Foram traçadas três possibilidades: uma primeira seria inserir esse acervo em uma universidade pública localizada no interior do nordeste, a fim de embasar atividades de ensino e pesquisa em Arqueologia; uma segunda seria a tripartição desse acervo em uma instituição pública em cada um dos estados envolvidos; e, ainda, uma terceira proposta associada à criação de Reservas Técnicas nas Superintendências Regionais do IPHAN.

As "Coleções de Referência", dotadas de 'apelo' museológico, seriam articuladas às ações de comunicação museológica. Seriam formadas dezesseis coleções com vestígios arqueológicos advindos das pesquisas na região de abrangência de cada polo. Essas coleções seriam cedidas por comodato pelas instituições responsáveis pelos acervos de pesquisa aos municípios que reunissem condições de recebê-las.

O território patrimonial em tela é caracterizado por uma ampla gama de referências culturais, sobre as quais serão projetadas coleções e narrativas construídas a partir das pesquisas arqueológicas realizadas na Ferrovia Transnordestina. Como vimos, o universo museológico é caracterizado por um reduzido número de instituições e pela instabilidade daquelas existentes. Esses fatores, associados à extensão do território em questão, envolvendo mais de dois milhões de pessoas, apontaram a necessidade de um programa de comunicação que 
atuasse em rede, a partir dos polos irradiadores sob uma perspectiva de itinerância.

A comunicação museológica foi construída a partir do conceito de educação popular, na concepção freiriana, ou seja, como o esforço de mobilização, organização e capacitação dos sujeitos (FREIRE, 1987).

Para Paulo Freire era preciso ler o mundo para poder transformá-lo (GADOTTI, 2002). A Arqueologia possibilita uma leitura específica do mundo, pautada na materialidade. Ora, em Pedagogia do Oprimido ao discutir as relações homens-mundo, os temas geradores e o conteúdo programático, Paulo Freire sublinha a importância da concretude, da existência para constituir o conteúdo programático (FREIRE, 1987). A materialidade analisada à luz da Arqueologia possibilita uma melhor compreensão dessa concretude. Destacamos ainda que as ideias de Paulo Freire são um contributo importante para a Sociomuseologia. A premissa de que "ninguém educa ninguém, ninguém educa a si mesmo, os homens se educam entre si, mediatizados pelo mundo" (FREIRE, 1987, p. 39), nos aponta para a necessária dialogicidade do programa.

Dessa forma, foram estabelecidas as seguintes estratégias do programa de Comunicação Museológica: Oficinas de Formação - Rede de Saberes; Rodas de Conversa e Exposição Itinerante.

As oficinas e rodas de conversa foram compreendidas como Círculos de Cultura, conceito que procura substituir a ideia de sala de aula por um espaço onde "todos estão à volta de uma equipe de trabalho que não tem um professor ou um alfabetizador, mas um animador de debates" (BRANDÃO, 1981, p.44). Nos círculos de cultura a troca é fundamental, mais que 
isso, é condição sine qua non para uma ação museológica libertadora. Para Paulo Freire a troca era fundamental, "o Diálogo não é apenas uma estratégia pedagógica, é um critério de verdade" (GADOTTI 2002, p. 54). A 'verdade' nasce do diálogo, do conflito com o olhar do outro.

Também foram propostos temas geradores, que, por sua vez, estão associados às questões, discussões e aos problemas colocados pelo presente. São temas amplos, organizados em círculos concêntricos, que, dentro de si, englobam temas mais focalizados, a saber: Ferrovia Transnordestina: eixo de reordenamento da paisagem; Arqueologia: leituras e usos da paisagem; Marcas da pedra; Agricultores do nordeste; Oleiras e oleiros: trabalho e arte; Comunidades quilombolas e patrimônio arqueológico; Arqueologia e Memória Indígena. Esses temas geradores foram trabalhados a partir das narrativas dos indivíduos, confrontadas com objetos arqueológicos geradores ${ }^{7}$.

\section{Considerações Finais}

O cenário contemporâneo brasileiro, no que concerne à Musealização da Arqueologia, é marcado por uma expressiva dinâmica no campo arqueológico e museológico, impulsionada por 'molas' propulsoras diferenciadas, levando a estranhamentos das mais diversas naturezas entre os campos.

\footnotetext{
O conceito de objeto gerador foi adaptado para o campo da Arqueologia de RAMOS (2004).
}

7

ZARANKIN, Andrés. (2002). Paredes que Domesticam: Arqueologia da Arquitetura Escolar Capitalista. Campinas: Centro de História da Arte e Arqueologia - Instituto de Filosofia e Ciências Humanas/ Fundação de Amparo à Pesquisa do Estado de São Paulo. 
No cenário museal, destaca-se uma política pública devotada ao incremento de processos museológicos, onde se enfatiza o papel social dos museus e a participação comunitária. No cenário arqueológico, destaca-se uma política de proteção ao meio ambiente, resultando no crescimento exponencial de pesquisas arqueológicas diretamente associadas ao licenciamento de empreendimentos, evidenciando uma forte ligação ao mercado. O número de instituições associadas ao patrimônio desvelado por essas pesquisas também é crescente.

Essas rotas, aparentemente irreconciliáveis, só poderão ser entrelaçadas a partir de uma transformação teórica também no seio da Arqueologia - a qual já pode ser vislumbrada em alguns trabalhos no país, e da definição de políticas públicas direcionadas ao equacionamento dos problemas museológicos decorrentes das pesquisas arqueológicas. Sim, porque toda a pesquisa arqueológica gera um problema museológico: coleções e/ou narrativas a serem preservadas e socializadas.

A proposta aqui sumarizada, devotada ao patrimônio arqueológico relacionado ao licenciamento da Ferrovia Transnordestina, ainda não foi implantada, a despeito dos esforços da equipe envolvida no projeto, tendo sido realizadas apenas as ações de comunicação, sob a rubrica de Programa de Educação Patrimonial, nos Polos de Salgueiro, Brejo Santo e Ouricuri, durante o ano de 2013. Infelizmente, a proposta de salvaguarda ainda não encontrou eco junto ao empreendedor e às autoridades competentes. Não obstante, enquanto proposta teórica e encaminhamento metodológico, a pesquisa apontou caminhos importantes.

Primeiro, apontei que os vestígios e as narrativas arqueológicas, desvelados pela pesquisa, devem ser integrados 
às demais referências patrimoniais das comunidades. Para adentrar $o$ universo de referências patrimoniais das comunidades envolvidas, faz-se necessário um método de trabalho pautado na dialogicidade, o que nos remete ao pensamento freireano.

Defendo que patrimônio arqueológico não é algo alheio ao contexto contemporâneo, pois é nele que construímos esse patrimônio. Assim, cabe a Arqueologia lidar com o presente tanto por meio de pesquisas que insiram esse presente como objeto de estudo, quanto integrado esse patrimônio às referências culturais das comunidades envolvidas. Ademais, a leitura contemporânea que as comunidades fazem de um patrimônio que parece "longínquo", caso das evidências associadas aos grupos indígenas, é imprescindível para a transformação de ideias preconcebidas sobre esses grupos e para o respeito aos direitos culturais desses grupos.

Um ponto muito próprio à educação popular é que o conhecimento do mundo é também feito através das práticas do mundo. Por meio dessas práticas que inventamos uma educação familiar às comunidades. Para tanto trabalhamos a partir de um universo, de um modo de conhecimento que é peculiar a elas. Não podemos prescindir das questões colocadas pelo presente para a construção de uma pedagogia libertadora. Entendemos que essa pedagogia libertadora é cara à Sociomuseologia. No caso do Programa de Musealização dos Recursos Arqueológicos da Ferrovia Transnordestina: como poderíamos partir do conhecimento que é peculiar aos nossos interlocutores se não tivéssemos considerado, e, efetivamente, realizado uma Arqueologia do Século XX? Essa Arqueologia possibilitou a construção de acervos materiais e narrativas que contam um 
pouco sobre esses contextos em transformação, frente à própria ação da Ferrovia Transnordestina. Esse processo só será possível, pois a Antropofagia Arqueológica e a Antropofagia Museológica partiram das mesmas premissas teóricas, políticas, éticas e, porque não, afetivas.

Por fim, uma ideia central desenvolvida nesse trabalho reside na necessária compreensão de que a antropofagia museológica se assenta sobre uma antropofagia arqueológica.

A antropofagia arqueológica é iniciada na coleta dos vestígios que fizeram parte da dinâmica social, econômica ou cultural das sociedades estudadas, são evidências que sobreviveram ao tempo e que conformam o contexto arqueológico. Essa antropofagia opera seleções, projetando apenas parcelas do contexto arqueológico na esfera patrimonial. No contexto museológico, os processos de salvaguarda e comunicação desses vestígios arqueológicos, também são antropofágicos, operam recortes e têm o poder de ressignificar essas evidências.

Não basta promovermos uma transformação na antropofagia museológica, é necessário também transformar a Arqueologia. O fazer arqueológico alinhado às perspectivas pósprocessuais tem a potência de alavancar práticas arqueológicas mais democráticas, possibilitando construções identitárias multivocais, a despeito do entrelaçamento entre pesquisa arqueológica e mercado. Por sua vez, o fazer museológico solidário com o referencial teórico da Sociomuseologia poderá lançar proposições plurais para a musealização dessas coleções e narrativas. Assim, defendo que a musealização da arqueologia envolve o exame crítico da hierarquia de valores presente na 
pesquisa arqueológica, uma vez que é aí que ocorre a aquisição do objeto arqueológico-museológico.

Outrossim, a interface entre Sociomuseologia e Arqueologias pós-processuais é tomada como caminho profícuo a ser trilhado, pois ambos os campos assumem o caráter subjetivo do conhecimento, questionam o papel social do patrimônio no mundo contemporâneo e investigam os interesses subjacentes à seleção das referências patrimoniais.

\section{Referências Bibliográficas}

ABREU, Regina; CHAGAS, Mário; SANTOS, Myrian S. (Orgs.). (2007). Museus, coleções e patrimônios: narrativas polifônicas. Rio de Janeiro: Garamond, MinC/ IPHAN/ DEMU. ALBUQUERQUE JÚNIOR, Durval Muniz de (2006). A Invenção do Nordeste e outras artes. São Paulo: Cortez Editora.

BOURDIEU, Pierre. (2004). Os usos sociais da ciência. Por uma sociologia clínica do campo científico. São Paulo: Editora UNESP. (Publicado Original 1997).

BRANDÃO, Carlos Rodrigues Brandão. (1981). O que é método Paulo Freire? Coleção Primeiros Passos, n.38. São Paulo: Editora Brasiliense.

BRUNO, Maria Cristina Oliveira. (1995). Musealização da Arqueologia: um estudo de modelos para o Projeto Paranapanema. Tese apresentada na Faculdade de Filosofia, Letras e Ciências Humanas da USP, São Paulo.

BRUNO, Maria Cristina Oliveira. (2000). A luta pela Perseguição ao Abandono. Tese apresentada na Faculdade de Filosofia, Letras e Ciências Humanas da USP. 
CALDARELLI, Solange Bezerra. (Org). (1996). Atas do simpósio sobre política nacional do meio ambiente e patrimônio cultural. Repercussões dos dez anos da Resolução CONAMA n.001/86 sobre a pesquisa e a gestão dos recursos culturais do Brasil. Goiânia: Universidade Católica de Goiás/ Instituto Goiano de Pré-História e Antropologia.

CHAGAS, Mário. (1998). Há uma gota de sangue em cada museu: a ótica museológica de Mário de Andrade. Cadernos de Sociomuseologia, n. 13. Lisboa: Edições Universitárias Lusófonas.

CHAGAS, Mário. (2004). Diabruras do saci: museu, memória, educação e patrimônio. MUSAS - Revista Brasileira de Museus e Museologia. Rio de Janeiro, v.1, n.1.

COSTA, Carlos Alberto Santos. (2007). A legalidade de um equívoco: acerca dos processos legais para a guarda de materiais arqueológicos em instituições museais. Anais do XIV Congresso da Sociedade de Arqueologia Brasileira, Florianópolis.

FOUCAULT, Michel. (1979). Microfísica do Poder. São Paulo: Graal.

FREIRE, Paulo. (1987). Pedagogia do oprimido. 17ạ. ed. Rio de Janeiro: Paz e Terra. (Publicado original em 1970).

GADOTTI, Moacir. (2002 ). Los aportes de Paulo Freire a la pedagogía crítica. Revista Educacíon, n.26, v.2.

MONTICELLI, Gislene. (2005). Arqueologia em obras de engenharia no Brasil: Uma crítica aos contextos. Tese de Doutorado apresentada à Pontifícia Universidade Católica do Rio Grande do Sul para a obtenção do título de doutor, Porto Alegre. 
MORAES WICHERS, Camila Azevedo de. (2010). Museus e antropofagia do patrimônio arqueológico: (des) caminhos da prática brasileira. Tese de doutoramento em Museologia, Universidade Lusófona de Humanidades e Tecnologias.

MOUTINHO, Mário. (1993). Sobre o conceito de Museologia Social. Cadernos de Sociomuseologia, $n^{\circ} 1$. Lisboa: Edições Universitárias Lusófonas.

PRIMO, Judite. (1999). Pensar contemporaneamente a Museologia. Cadernos de Sociomuseologia, $\mathrm{n}$ ㅇ⒗ Lisboa: Edições Universitárias Lusófonas.

PRIMO, Judite. (2007). A Museologia e as Políticas Culturais Européias: 0 Caso Português. Tese apresentada a Universidade Portucalense Infante D. Henrique para obtenção do título de doutor, Porto.

REIS, Jose Alberione dos. (2004). Não pensa muito que dói um palimpsesto sobre teoria na Arqueologia brasileira. Tese apresentada ao Instituto de Filosofia e Ciências Humanas da Universidade Estadual de Campinas, Campinas.

SALADINO, Alejandra. (2010). Prospecções: o patrimônio arqueológico nas práticas e trajetória do IPHAN. Tese apresentada ao Programa de Pós-Graduação em Ciências Sociais da Universidade do Estado do Rio de Janeiro para obtenção do título de doutor, Rio de Janeiro.

SHANKS, Michael \& TILLEY, Christopher. (1992). ReConstructing Archaeology. London \& New York: Routledge (Publicado Original 1987).

SHANKS, Michael. (2004). From a postprocessual to a symmetrical archaeology. Disponível em: http://traumwerk.stanford.edu:3455/symmetry/822. Acedido em 2 de Dezembro de 2010. 
